\title{
A HERMENÊUTICA DigITAL COMO HERMENÊUTICA Do SUJEITO ${ }^{1}$
}

\author{
Alberto Romele ${ }^{2}$
}

\begin{abstract}
RESUMO: Neste artigo, o autor debruça-se sobre o estatuto do sujeito e da identidade pessoal no contexto do digital. Na primeira secção do texto, ele desenvolve a sua abordagem geral dos meios e tecnologias digitais, a qual designa de "hermenêutica digital". Destaca nela três perspectivas, nomeadamente a desconstrutiva, a epistemológica e a abordagem ontológica. Na segunda parte do texto, o autor debruça a sua atenção sobre a hermenêutica digital enquanto hermenêutica do sujeito. Compara aí a identidade narrativa de Paul Ricoeur com o habitus de Pierre Bourdieu. A sua primeira tese defende que o habitus pode ser compreendido como um conceito subjectivador que negligencia uma parte importante do sujeito. Nesse sentido, a identidade narrativa oferece uma solução para tal negligência. A sua segunda tese defende que os meios e tecnologias digitais dos dias de hoje se encontram mais próximos do habitus bourdieusiano que da identidade narrativa ricoeuriana. Por outras palavras, as máquinas e tecnologias digitais são "máquinas geradoras de habitus", tanto na sua estrutura como nos seus efeitos.
\end{abstract}

Palavras-chave: Hermenêutica Digital. Sujeito. Emaginação. Habitus. Identidade Narrativa.

\section{INTRODUÇÃo}

Neste artigo, ocupar-me-ei com o estatuto do sujeito e da identidade pessoal no contexto digital. A perspectiva que irei desenvolver não será, porém, aquela que caracteriza o trabalho de um académico das Ciências Sociais ou das Ciências da Comunicação. Nessas disciplinas, poderia, por exemplo, fazer referência às publicaçôes de certos autores, como Cardon (2008) e Georges (2009), pois, muito embora as suas publicaçóes se encontrem, hoje, desactualizadas, elas continuam ainda a fornecer importantes instrumentos para a análise empírica dos efeitos que os meios e tecnologias digitais, nomeadamente as plataformas de social media, exercem sobre nós e sobre

1 Tradução portuguesa de Ângelo Milhano.

2 Pesquisador no Internationales Zentrum für Ethik den Wissenschaften (IZEW) - Universität Tübingen, Tübingen - Alemanha. (D) https://orcid.org/0000-0001-8648-6619 Email: romelealberto@gmail.com

https://doi.org/10.1590/0101-3173.2021.v44dossier.10.p185

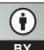

This is an open-access article distributed under the terms of the Creative Commons Attribution License. 
as nossas identidades. Neste texto, irei, contudo, privilegiar consideraçóes teoréticas à análise de um conjunto de estudos de caso. Vou sobretudo defender que, apesar das suas diversas nuances, os meios e as tecnologias digitais possuem, hoje, algo em comum, tanto na sua estrutura como nas consequências que acarretam para nós.

$\mathrm{O}$ artigo será desenvolvido por duas secçóes. Na primeira, vou apresentar a minha abordagem aos meios e tecnologias digitais, a qual denominei "hermenêutica digital" (2020). Irei distinguir três perspectivas diferentes, sob as quais se desenvolve a hermenêutica digital: (1) desconstrutiva, (2) epistemológica e (3) ontológica. No entanto, tal não significa que a hermenêutica digital não tenha outras potenciais perspectivas que se encontram ainda por explorar. De entre elas, uma será precisamente a da compreensão da hermenêutica digital enquanto hermenêutica do sujeito.

$\mathrm{Na}$ segunda secção, vou reflectir sobre as questôes da identidade pessoal e da subjectivação. Irei comparar o conceito de "identidade narrativa" de Paul Ricoeur com o conceito de habitus de Pierre Bourdieu. A minha tese defenderá que o habitus pode ser compreendido como um processo de subjectivação que acaba por negligenciar uma parte importante do sujeito, e que a "identidade narrativa" fornece, para tal, uma solução. Ainda nessa secção, irei também sustentar que as tecnologias e os meios digitais se encontram hoje mais próximos da concepção bourdieusiana de habitus que da identidade narrativa ricoeuriana. Por outras palavras, irei defender que as máquinas e as tecnologias digitais são elas mesmas "máquinas criadoras de habitus", tanto na sua estrutura como nas suas repercussóes. Na conclusão, irei dar conta de três possíveis respostas ao problema da nossa habituação online.

\section{Hermenêutica digital}

A expressão "hermenêutica digital" existe já há algum tempo. Explicita Capurro (2010, s/n):

A Hermenêutica confronta-se hoje com o desafio que é lançado pelas tecnologias digitais, transformando-se naquilo que eu designo de hermenêutica digital [...] $\mathrm{O}$ desafio que a internet representa para a hermenêutica manifesta-se sobretudo na sua relevância social para a criaçáo, comunicaçáo, e interpretaçáo do conhecimento. 
Capurro (2010, s/n) desenvolve, com particular interesse, "os dois lados de um mesmo processo de enfraquecimento da tecnologia moderna." Por um lado, dá-se um enfraquecimento do papel do intérprete, na medida em que este se embrenha numa cada vez mais complexa rede de humanos e não humanos, e que apenas consegue controlar parcialmente. Por outro lado, afirma (2010, $\mathrm{s} / \mathrm{n}$ ) que "as tecnologias da informação são tecnologias frágeis, uma vez que lidam com as 'conversaçóes humanas'." Ao longo deste trabalho, vou sustentar que a primeira afirmação é hoje ainda válida, mas que a segunda perdeu, entretanto, o seu momentum. De facto, as "conversaçóes humanas" e, de uma forma geral, todas as formas de produção de conteúdos e de representação online do sujeito, encontram na prática de "alimentar o monstro" a sua única função, no prover as máquinas algorítmicas com a infinidade de dados de que necessitam para melhorar a sua performance, em termos de análise e previsão. Nesse sentido, os discursos humanos não fragilizam as tecnologias digitais, fortalecendo-as, antes, no que diz respeito à habituaçáo que criam em nós.

Nas minhas mais recentes investigaçóes (ROMELE, 2019), fiz uso da expressão "hermenêutica digital" para, a partir dela, destacar três significados distintos:

(1) Em primeiro lugar, porque o termo possui um sentido desconstrutivo ou até mesmo destrutivo. De entre as diversas mediaçóes que podem ser criadas entre a humanidade e o mundo, a hermenêutica tem tido apenas em conta a linguagem. De acordo com Latour (1993, p. 63), a grandiosidade das filosofias e das teorias da linguagem do século XX, tal como é o caso da hermenêutica, manifesta-se na forma como dignificam devidamente as mediaçóes, uma vez que deixaram de as considerar como veículos puros através dos quais um orador atribuí significado ao mundo, ou vice-versa. Contudo, a sua fraqueza mostra-se na forma como privilegiaram a linguagem como o único mediador ou, no mínimo, como o paradigma de todas as mediaçóes possíveis.

A hermenêutica de Paul Ricoeur configura-se, nesse sentido, como um caso paradigmático. Por um lado, e enquanto representante da tradição ontológica da hermenêutica, Ricoeur é certamente o autor que mais interesse demonstrou na externalização e materialização da linguagem: sinais, metáforas, narrativas, textos, e a escrita em geral. É também por essa via que se manifesta a preferência de Ricoeur pela "via longa" da hermenêutica, por oposição à "via curta" de Martin Heidegger. Por outro lado, Ricoeur nunca lidou realmente com a dimensão material dos suportes de transmissão de significado, tendo 
acabado por universalizar materializaçóes e externalizaçóes específicas, para poder assim compreender todas as outras.

Considere-se, por exemplo, a noção ricoeuriana de identidade narrativa, a qual se caracteriza tanto pela sua monolinearidade como pela sua monomediatização. $\mathrm{O}$ conceito é monolinear, porque se baseia sob um modelo aristotélico (tal como apresentado na Poética) e sob um modelo bíblico, de acordo com os quais todas as narrativas têm que se compor a partir de um enredo (mise en intrigue) que organiza os elementos heterogéneos de uma situação sob uma ordem específica, isto é, devidamente fechados entre um princípio e um fim. A monomediatização, por seu turno, fundamentase no facto de a identidade narrativa se construir a partir do modelo do texto impresso. De acordo com De Mul (2010), enquanto a leitura do texto impresso tende a ser unívoca, o texto digital revela-se potencialmente diferente a cada leitura que dele se faz. Para De Mul, a Web é uma base de dados de um número indefinido de histórias potenciais. Para além disso, no digital, a escrita é apenas um de entre os vários meios e possibilidades de expressão.

Por consequência, torna-se também importante distinguir entre a dimensão descritiva e a dimensão prescritiva da identidade narrativa, em Ricoeur. Acredito que a monolinearidade e a monomediatização podem ser criticadas sem se perder, muito embora adaptando, a sua dimensão descritiva, sendo esta a razão pela qual irei ainda recorrer de tal noção, na segunda secção deste artigo. Contudo, as tecnologias digitais acabam por destacar a natureza problemática da dimensão prescritiva. De facto, a multilinearidade e a multimediatizaçáo são paradigmas que acarretam menos frustração na compreensão e julgamento das identidades pós-modernas.

(2) A hermenêutica acabou também por desempenhar um papel positivo na minha compreensão dos meios e das tecnologias digitais, uma vez que o "idealismo materialista" não constitui um limite intrínseco da hermenêutica. De acordo com Ihde (1990), os textos são uma de muitas tecnologias hermenêuticas, as quais se caracterizam por criar representaçôes do mundo que devem ser interpretadas para poder aceder a esse mesmo mundo. Tal é o caso, por exemplo, do cockpit de uma aeronave, sobretudo quando um piloto se vê confrontado com condiçóes meteorológicas adversas. Outros possíveis exemplos serão os termómetros, microscópios electrónicos e telescópios, e todos os meios e tecnologias digitais que transformam os sinais e os dados em algo que pode ser por nós interpretado e manipulado. 
Os meios e as tecnologias digitais são também eles hermenêuticos, porque lidam sobretudo com sinais. Contudo, o simbolismo digital é muito específico, pois se baseia numa (1) dupla suspensão do significado e da referência que permite (2) uma manipulação formal e mecânica dos sinais (BACHIMONT, 2011). É aqui onde radica a sua força, visto que se tornam assim capazes de lidar com qualquer tipo de entidade no mundo. Poderse-á por isso dizer que a hermenêutica digital se apresenta, nesse sentido, como verdadeiramente universal. Porém, é também aqui onde reside a sua fragilidade, já que os sinais digitais acabam por negligenciar todos os contextos da sua produção e recepçấo ou, noutras palavras, a lacuna que existe entre "mapa" e "território".

Hoje em dia, existe uma tendência sociológica em acreditar que os meios e tecnologias digitais podem concretizar e conhecer tudo, porque são capazes de tudo manipular. A hermenêutica, sobretudo no que diz respeito à sua formulação ricoueriana, convida-nos antes a praticar a arte do distanciamento. Enquanto as pessoas se demonstram normalmente entusiasmadas com as capacidades das impressoras 3D, uma atitude hermenêutica evidencia as diversas dificuldades e limitaçóes, tanto em termos de hardware como de software, que a impressão 3D ainda enfrenta, nos dias que correm.

Enquanto os sociólogos do digital usam os dados e os métodos digitais na sua abordagem à realidade social, a hermenêutica digital faz por destacar as várias limitaçóes de uma tal abordagem — os dados digitais, especialmente aqueles que advêm das redes sociais, como é o caso do Twitter, não são representativos de uma população inteira; o uso de métodos digitais específicos é influenciado pelas competências técnicas, recursos financeiros, enquadramentos teoréticos, entre outros elementos possíveis. Em Romele, Severo e Furia (2020), analisámos o uso dos dados digitais, nomeadamente tweets, para estudar a opiniáo política. Recorremos, em particular, do modelo ricouriano da tríplice mimesis, para descrever a circularidade hermenêutica entre os dados, os métodos e o fundo conceptual: 
Figura 1: A tríplice mimesis e o uso de tweets para estudo da opinião política

\begin{tabular}{llll} 
Abordagem & Prefiguração (dados) & $\begin{array}{l}\text { Configuração } \\
\text { (método) }\end{array}$ & $\begin{array}{l}\text { Refiguração (forma } \\
\text { conceptual) }\end{array}$ \\
\hline (1) Preferência & $\begin{array}{l}\text { Tweet como unidade } \\
\text { (volume de tweets) }\end{array}$ & $\begin{array}{l}\text { Estatística } \\
\text { Análise da disposição } \\
\text { afectiva base (léxico) }\end{array}$ & Opinião das massas \\
\hline & $\begin{array}{l}\text { Tweet como conteúdo } \\
\text { (palavras e imagens } \\
\text { dentro do tweet) }\end{array}$ & $\begin{array}{l}\text { Análise da disposição } \\
\text { afectiva avançada }\end{array}$ & $\begin{array}{l}\text { (aprendizagem } \\
\text { supervisionada e não } \\
\text { supervisionada) }\end{array}$ \\
\hline
\end{tabular}

(3) Interacção

Tweet como interacção (contexto dos tweets)

Análise de rede

Opinião activada

Fonte: Romele, Severo e Furia (2020, p. 83).

A noção de rasto digital desempenha um papel central na minha investigação. Para determinados autores, como Levinas ou Derrida, o conceito de rasto diz respeito a uma espécie de epistemologia paradoxal, ou até mesmo impossível; para Ricoeur, o uso do termo é feito como forma de escape a uma alternativa danosa. O primeiro refere-se à compreensão do rasto como marca e efeito de uma causa. O segundo defende que o rasto é significação pura, um símbolo do outro, que é, na sua essência, inacessível. Quando discute Levinas, Ricoeur declara que partilha com ele a ideia de que o rasto se distingue de todos os sinais que se organizam em sistemas, uma vez que perturba a sua ordem. No entanto, dá preferência à ideia de um outro relativo à de um outro histórico (RICOEUR, 1988, p. 125). Conforme Ricoeur, o rasto é, por isso, a matriz de uma epistemologia difícil, no entanto, ainda possível.

Quanto aos rastos digitais, seria ainda possível argumentar que esse conceito pode ser mobilizado de modo a evitar duas posições extremas. Por um lado, daqueles que acreditam que o rasto digital permite, finalmente, o preenchimento da lacuna que existe entre as Ciências Sociais e as Ciências Exactas. Por outro, daqueles que defendem cegamente a impossibilidade absoluta de reduzir o humano às suas manifestaçóes digitais. A noção de rasto digital traz consigo o evidenciável (no sentido do "paradigma 
indiciário (indiciaire)" de Ginzburg) e, por isso, o carácter incerto das epistemologias digitais. ${ }^{3}$

(3) Ao longo das minhas investigações, propus também um empreendimento da hermenêutica digital por uma espécie de "viragem ontológica". Por ser ontológica na sua orientação, a hermenêutica digital ocupa-se com o papel que as tecnologias digitais desempenham hoje, na nossa constituição enquanto "animais interpretativos". A hermenêutica digital questiona também, e em que medida, nos encontramos hoje, e cada vez mais, a lidar com máquinas interpretativas. Essa foi a razão pela qual acabei por introduzir o conceito de Emaginação (emagination) no meu trabalho.

Derrida cunhou o termo différance, um erro deliberado de ortografia na palavra différence, que se pronuncia, contudo, da mesma forma. A sua intenção procurava denunciar o fonologocentrismo, isto é, a predilecçáo pelo discurso oral em detrimento do escrito, e também subverter essa tendência. Do mesmo modo, Emaginaçáo procura mostrar-se como uma crítica das crenças mais comuns, segundo as quais a imaginação se encontra "nas nossas cabeças", e de que existe uma lacuna ontológica entre os humanos e as máquinas, que se manifesta nas capacidades humanas da imaginação e da criatividade.

Tenho, em primeiro lugar, argumentado que o esquematismo não pode ser considerado "uma arte que radica nas profundezas da alma humana". A síntese entre a receptividade e a espontaneidade acontece "fora das nossas cabeças": nas expressôes linguísticas e nas formas escritas, mas também nas técnicas incorporadas e nas tecnologias. Por outras palavras, defendo que a imaginação humana se encontra sempre disposta no exterior - e, por consequência, na matéria, na sociedade, na história e na técnica.

Em segundo lugar, tenho vindo a afirmar que a nossa imaginação produtiva se corresponde pouco com a de um "engenheiro" e muito mais com a de um "artesáo", uma vez que lida sempre com o que quer que seja "que se encontra à máo". Poder-se-á mesmo dizer que o engenheiro-imaginativo já não é um mito. Hoje em dia, as tecnologias digitais, especialmente aquelas que se aplicam às humanidades, estão precisamente a desmitologizar as reivindicações humanas no que concerne à novidade, criatividade $\mathrm{e}$ à autenticidade. Considere-se o trabalho em literatura quantitativa de

${ }^{3}$ Para Ginzburg (assim como para Ricoeur), o paradigma indiciário é característico das Ciências Sociais e das Ciências Humanas. O uso abundante dos rastos digitais nas ciências duras mostra como o paradigma indiciário vai, hoje, muito para além dos limites das Ciências Sociais e Humanas. Quanto às ciências centradas sobre os dados, veja-se, em particular, LEONELLI (2016). 
Franco Moretti, em analítica cultural por Lev Manovitch, e outras recentes publicações que permitem, por exemplo, quantificar a reputação e o sucesso na arte (FRAIBERGER et al., 2018).

Esses exemplos demonstram como a imaginação humana e a digital se encontram cada vez mais próximas uma da outra, o que, por sua vez, não implica que elas sejam iguais uma à outra - mais do que ontologicamente, as suas diferenças deverão ser compreendidas nos termos do grau e da emergência das suas propriedades. Recorri, mais particularmente, da distinção proposta por Hans Lenk (1995), que estipula seis níveis diferentes da interpretaçáo para indicar que, para cada um desses níveis, se torna necessário estabelecer quais deles são, ou podem ser, implementados em tecnologias digitais, e quais deles continuam sob a prerrogativa humana. A hermenêutica digital deverá também investigar as formas emergentes de interpretação digital que pouco têm em comum com as formas com as quais o ser humano lida com o mundo.

As minhas investigações anteriores em hermenêutica digital não esgotam esse campo, e muitas outras perspectivas poderão ainda ser desenvolvidas. Nos dois últimos anos, interessei-me particularmente sobre os "imaginários tecnológicos”, que dizem respeito ao conjunto de discursos, representaçóes visuais e crenças nas quais as tecnologias se encontram já sempre embutidas. Flichy (2007, p. 8-12) se valeu da articulação entre ideologia e utopia de Ricoeur para compreender o papel do "imaginário" na acção tecnológica. De acordo com Flichy, o "imaginário" não se opóe ao processo de inovação tecnológica. Ele suporta-o, de acordo com um esquema que vai da utopia à ideologia: 
Figura 2: O papel do “imaginário" na acção técnica.

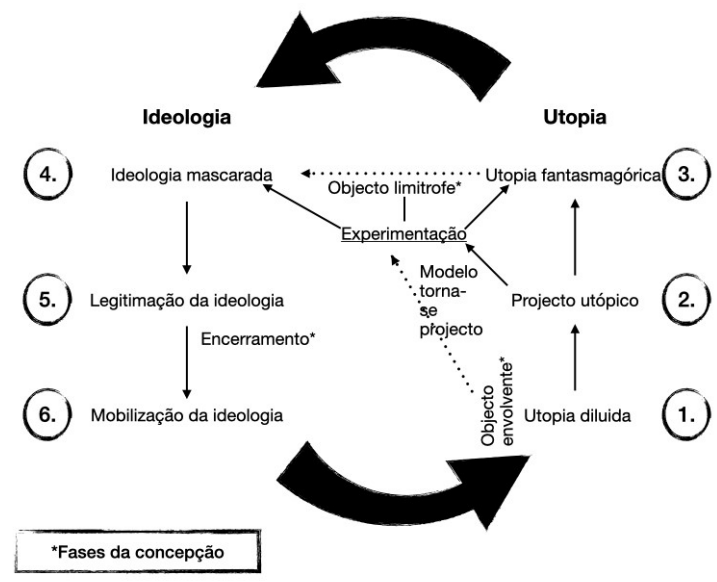

Fonte: FLICHY, 2007, p.10.4

\section{A noção dos "imaginários" tecnológicos demonstra como as tecnologias} são sempre mais que a soma total dos seus componentes materiais. Naquilo

${ }^{4}$ A descrição que Flichy fornece para o seu esquema é a seguinte: "A função subversiva da utopia, aquela que permite o alcance do seu espectro total de possibilidades a ser exploradas, poderá ser introduzida no início do processo [...] Os projectos aqui concebidos são bastantes diversos, muitas vezes opostos, e algumas vezes simplesmente justapostos [... $\mathrm{Na}$ segunda fase, uma alternativa realista aos objectos técnicos já existentes é construída à medida que os modelos que são lapidados na fase precedente se transformam em projectos completos. [...] No final desta fase, a reflexão utópica pode ser desenvolvida em dois sentidos. Ou é incorporada num projecto experimental, ou se transforma em fantasia pura. [...] Quando os utopistas se transformam em experimentalistas são confrontados não apenas com a técnica mas também com outros actores sociais que dela possuem uma visão diferente. [...] Necessitam, neste sentido, de construir um objecto limítrofe, um compromisso que pode ser utilizado de modo a associar múltiplos parceiros, de forma suficientemente folgada, para que todos possam beneficiar, mas também o suficientemente sólida para que o dispositivo funcione. [...] A fase experimental não diz apenas respeito ao período de tempo que é necessário para desenvolver a técnica e os seus usos, mas também à fase na qual o discurso utópico é reconstruído de forma a fundamentar as suas reivindicaçốes a partir dos exemplos dados pelas experiências que foram realizadas. [...] A viragem operada pelo mito irá, eventualmente, transformar a utopia numa ideologia. Nesta nova fase, vários aspectos da realidade serão prontamente ocultados de modo a promover a nova técnica. Refirome, neste caso, à ideologia mascarada. A ideologia técnica irá permitir a possibilidade de legitimar o novo sistema técnico. À medida que ganha rigidez, as alternativas serão postas de parte, resultando naquilo que os economistas designam de encerramento tecnológico. Neste estádio, introduzo o termo legitimação da ideologia. Por fim, e tendo em conta que a função positiva da ideologia consiste em mobilizar os actores que estáo aqui envolvidos - tanto os produtores da tecnologia como os seus utilizadores —, designo o estádio final como uma mobilização da ideologia.” (FLICHY, 2007, p. 10). 
que diz especificamente respeito às tecnologias digitais, como é o caso dos algoritmos de aprendizagem maquinal e de inteligência artificial, poder-se-á dizer que a sua eficiência depende apenas em parte da sua performance. Um papel fundamental é, de facto, desempenhado pelas narrativas, pelos medos e entusiasmos que nelas se incorporam e que elas enquadram, sob uma nova perspectiva.

\section{Hermenêutica digital do sujeito}

O que resta deste artigo dedica-se a uma outra questão, nomeadamente à "hermenêutica digital do sujeito". Essa perspectiva consiste fundamentalmente numa análise do impacto que as tecnologias e meios digitais possuem sobre os processos de subjectivação. Claramente, um trabalho empírico sobre esse tema iria destacar um número indefinido de variaçôes. Contudo, tenho a impressão de que existe uma tendência comum na forma como as tecnologias e os meios digitais, como se encontram hoje configurados, operam sobre nós.

A "hermenêutica do sujeito" é uma expressão que Foucault utilizou nos seus cursos mais tardios no Collège de France, nos quais desenvolveu o seu interesse pela forma como o sujeito se subjectiviza a si mesmo. Numa entrevista que concedeu, em 1984, Foucault acaba por concordar com os seus entrevistadores, quando lhe indicam que "se manifesta agora [no seu trabalho] uma espécie de viragem: estes jogos de verdade já não se encontram preocupados com as práticas coercivas, mas antes com as práticas de autoformação do sujeito.” (FORNET-BETANCOURT et al., 1987, p. 113). Contudo, e é isto o que torna a perspectiva de Foucault particularmente interessante, ele também sublinha que

[...] estas práticas [do sujeito] não são, porém, algo que o indivíduo inventa por si próprio. Elas assentam sobre os padrôes que o sujeito encontra na sua cultura, e que são propostas, sugeridas, e impostas sobre ele pela sua cultura, a sua sociedade e o seu grupo social. (FOUCAULT apud FORNET-BETANCOURT et al., 1987, p. 122).

Por outras palavras, qualquer autoconstrução do sujeito é sempre já uma heteroconstrução, sendo precisamente essa articulação entre passividade e actividade o que me interessa nesse contexto e que também encontro na 
perspectiva de Ricoeur, mais particularmente na sua noção de identidade narrativa. ${ }^{5}$

De forma a desenvolver a minha posição por inteiro, proponho confrontar a identidade narrativa de Ricoeur com o habitus de Bourdieu. Irei sustentar que, mesmo tendo em conta a retórica do potencial de empoderamento da Web 2.0 que, no passado, dominou a literatura sobre esse tópico, os efeitos da subjectivação dos meios e tecnologias digitais se encontram hoje mais próximos do habitus de Bourdieu que da identidade narrativa ricoeuriana.

Ricoeur começou por desenvolver o seu conceito de identidade narrativa no final do terceiro volume de Tempo e Narrativa, lançado, no francês original, em 1985. Ricoeur (1988, p. 246) identifica a identidade narrativa enquanto ipse: "A diferença entre idem e ipse nada mais é que a diferença entre identidade substancial ou formal, e a identidade narrativa." Em O Si Mesmo como Outro, publicado em francês cinco anos mais tarde, Ricoeur vai além de tal alternativa e apresenta a identidade narrativa como a articulaçáo entre idem (mesmidade) e ipse (ipseidade) — no sexto estudo do livro, acaba por descrever a identidade narrativa como uma função mediadora que gera e tolera variações imaginativas (RICOEUR, 1992, p. 148).

No geral, a identidade narrativa faz referência ao facto de as nossas identidades se constituírem narrativamente. Tal quer dizer que existe uma permanência das nossas identidades, apesar de todas as mudanças que se dão, ao longo do tempo; de facto, a história é uma "concordância de discordâncias", a qual permite manter unidos vários elementos heterogéneos, através da frágil dinâmica do enredo que opera a síntese do heterogéneo. Para além disso, a noção sugere ainda que as nossas identidades se constituem a partir das histórias que contamos e que também ouvimos, lemos ou vemos, e que eventualmente se transformam em exemplos de existência individual ou social.

\footnotetext{
5 Por razōes de extensão, não me é possível desenvolver esse ponto integralmente, no entanto, defendo que as noçốes de subjectividade de Ricoeur e Foucault necessitam uma da outra. A perspectiva de Ricoeur necessita da de Foucault, na medida em que lhe oferece uma percepção - histórica e socialmente, mas também técnica e tecnologicamente - mais bem situada da constituiçáo do sujeito. No sentido inverso, defendo que a perspectiva de Foucault necessita da de Ricoeur, na medida em que a antropologia filosófica do segundo sugere que deveremos continuar à procura de uma certa autonomia no sujeito, para além de todas as suas heterodeterminaçóes - sobre as similaridades entre Ricoeur e Foucault, veja-se Barthélémy (2010) e Leibovici (2014). Para uma leitura foucaultiana da antropologia filosófica de Ricoeur, isto é, uma leitura nos termos de um "renovado interesse sobre o cuidado com o sujeito", veja-se Michel (2014, p. 101-122).
} 
Esse exemplo encontra-se fundamentalmente relacionado com a passividade que em nós reside, na presença do outro em nós mesmos, uma vez que, (1) para contar uma história, é sempre necessário torná-la potencialmente disponível para outrem, posto que (2) não possuímos qualquer tipo de monopólio sobre as nossas histórias. O outro poderá sempre contar sobre nós histórias pertinentes ou impertinentes; com efeito, o outro não é apenas o outro próximo (prochain), isto é, as pessoas que nos são chegadas, mas também o outro distante (lointain), a sociedade e a tradição (literária) na qual nos encontramos imersos. De acordo com Ricoeur (1988, p. 247), a identidade narrativa confirma que

[...] o sujeito do auto-conhecimento não é o ego egoista e narcisista [...] [mas] o fruto de uma vida examinada [...]. E uma vida examinada é, em grande medida, uma que foi purgada, que foi clarificada pelos efeitos catárticos das narrativas, sejam elas históricas ou ficcionais, que foram sendo convencionadas pela nossa cultura.

Tal como já referi, em O Si Mesmo como Outro, Ricoeur apresenta a identidade narrativa como uma mediação entre a mesmidade e a ipseidade. De modo a descrever esses dois polos, faz recurso a duas expressóes "que são, simultaneamente, descritivas e emblemáticas": o carácter e a capacidade de manter a palavra. O carácter é um conjunto de marcas distintivas que permitem a reidentificação de um indivíduo humano como sendo o mesmo. A "capacidade de manter a palavra", diz-nos Ricoeur (1992, p. 124), parece mostrar-se como um desafio contra o tempo, uma negação da mudança, mesmo que mude de opiniâo ou de inclinação, "irei manter-me firme". Coloco, por isso, como hipótese, que a mesmidade, tal como descrita por Ricoeur, se apresenta bastante próxima do modo como Bourdieu compreende o habitus. Para Ricoeur, o carácter é um conjunto de disposiçóes duráveis que atribuímos a uma pessoa. O habitus bourdieusiano é, igualmente, um sistema de disposiçóes duráveis e transponíveis.

Poderá, como é claro, defender-se que o carácter ricoeuriano continua pessoal, enquanto o habitus bourdieusiano se compreende como social. No entanto, não nos podemos esquecer que o habitus bourdieusiano, embora social, é também apropriado e personalizado. Por outras palavras, cada indivíduo, enquanto membro de um grupo social ou de uma classe, possui o seu estilo. Para além disso, enquanto o carácter ricoeuriano é personalizado, não deixa de ser o resultado de um processo de habituação social e contextual. 
De facto, a distinção entre mesmidade e ipseidade poderá ser lida, em termos hermenêuticos, a partir da diferença que se estabelece entre interpretaçóes "neutras" ou "mortas" e as interpretaçôes "vivas". As interpretações neutras ou mortas são aquelas formas de lidar com o mundo que foram reiteradas tantas vezes que acabaram por se tornar parte do nosso aparato cognitivo, cultural e gestual — no entanto, não nos podemos esquecer de que, no início, tivemos que as aprender, tal como o é o caso da aprendizagem da fala, da conduçáo, na capacidade de preparar café ou de amar sem ser possessivo. As interpretaçôes vivas são, pelo contrário, causadas pelo encontro com algo inesperado ou, por alguma razão, problemático, pois os nossos esquemas (ou habitus) não podem ser sobre elas aplicados. A nossa existência enquanto animais interpretativos é construída a partir da articulação entre essas duas dimensôes: na maioria das vezes, mantemo-nos dentro dos limites dos nossos hábitos, das nossas interpretaçoos neutras ou mortas; mas, de quando em vez, pelo menos enquanto horizonte de possibilidade, conseguimos levar a cabo interpretações vivas, sempre e quando nos confrontamos com uma situação problemática que não se encaixa nos nossos esquemas, porém, com a qual podemos e queremos envolver-nos.

Conforme Bourdieu, o habitus é aquilo que faz com que um grupo social ou uma classe se constituam como o grupo social ou a classe que são; isto é, aquilo que faz com que as decisóes individuais e as açóes que cada membro de um grupo social ou de uma classe tomam, perante algumas situaçóes e objectos específicos, se assemelhem entre si. Nas palavras do sociólogo francês, o habitus é "uma orquestração não guiada que fornece regularidade, unidade, e sistematicidade às práticas de um determinado grupo ou classe, mesmo na ausência de qualquer organização imposta espontânea ou externamente sobre os projectos individuais." (BOURDIEU, 1977, p. 80). É de sublinhar que, para Bourdieu, o habitus não forja apenas acções e reacçôes, mas também os desejos e as aspiraçôes mais autênticas dos indivíduos.

Para Ricoeur, a mesmidade é apenas uma parte das nossas identidades — ou, em termos hermenêuticos, das nossas práticas interpretativas. De acordo com Bourdieu, a ipseidade não é mais que uma ilusão. Ele fala, por exemplo, de uma "ilusão biográfica" (1986). Segundo Bourdieu, os actores sociais nunca são capazes de dizer a verdade acerca de si mesmos, porque todas as histórias que criam e contam sobre si não são mais que uma "criação artificial de significado". Apenas um sociólogo se mostra capaz de revelar as acçóes dos actores sociais, uma vez que se encontra na posse dos métodos e das 
práticas que são necessárias para cultivar a distância entre os actores sociais e as situaçóes nas quais se encontram imersos. ${ }^{6}$

$\mathrm{Na}$ crítica que lança à ilusão biográfica, Bourdieu não toma Ricoeur como o seu alvo, mas, antes, a tentativa de alguns sociólogos em dar voz às intençóes e às histórias dos actores sociais. Truc (2011, p. 151) referese à existência de uma "viragem narrativa" na sociologia francesa, mais particularmente entre os representantes da sociologia pragmática, tais como Boltanski e Thévénot ${ }^{7}$, em grande medida influenciados pelo trabalho de Ricoeur. A sua viragem epistemológica consistiu sobretudo na recuperação dos métodos biográficos. Na sua origem, encontra-se uma certa insatisfação com a noção bourdieusiana de habitus e a abordagem à identidade pessoal que ela implica. Por exemplo, no decorrer de uma mesa redonda dedicada ao "Efeito Ricoeur sobre as ciências humanas" (L'effet Ricoeur dans ler sciences humaines), Thévénot (2006, s/n) salientou que

[...] a concepção da pessoa e da sua identidade é subdesenvolvida nas ciências sociais em favor da mesmidade. A estabilidade da identidade que os sociólogos concebem nos termos de um habitus colectivo [...] impede uma consideração de um outro pólo de identidade, de ipseidade, que Ricoeur ligou com a promessa.

Para resumir, poder-se-á dizer que a sociologia contemporânea seguiu o caminho que vai de Bourdieu para Ricoeur e fez um esforço em articular a mesmidade com a ipseidade. Isto, como é claro, não se corresponde com a exaltação ingénua do sujeito e da sua autonomia. De facto, e tal como já referi, de uma perspectiva ricoeuriana, dar voz aos actores e às suas histórias não quer dizer que esses actores tenham o monopólio destas e outras histórias que se constroem acerca deles.

A minha hipótese, que é também a hipótese central deste artigo, sustenta que os meios e as tecnologias digitais têm, antes, seguido o sentido contrário, da ipseidade para a mesmidade. A literatura em torno do digital, nos anos 1980 e 1990, principalmente aquela que é dedicada à Web, insiste sobre o potencial de empoderamento dos indivíduos e das suas identidades. No decorrer dos anos 2000, emergiu a Web 2.0, ou a social web. Com a sua

\footnotetext{
${ }^{6}$ No último curso que leccionou no Collège de France, Bourdieu reconhece, contudo, que no campo sociológico, o distanciamento não é fácil. Por essa razão, acaba por defender uma prática muito específica de "reflexividade".

${ }^{7}$ Sobre Bourdieu e Ricoeur, veja-se ainda Michel (2014, p. 1-29) e Corcuff (2005).
} 
emergência, os académicos concentraram-se sobretudo nas relaçóes entre utilizadores, a par com as consequências positivas e negativas que delas advêm. Ao longo da última década, a literatura e as metodologias de análise têm sido dominadas pelas questôes levantadas pelo big data e, mais recentemente, também pelos algoritmos. A minha tese defende que os meios e tecnologias digitais se transformaram, entretanto, em "máquinas criadoras de habitus".

May (2019) assinalou recentemente que as imagens digitais nem sequer podem ser consideradas imagens. De um ponto de vista ontológico, as imagens digitais são muito diferentes, tanto das fotografias como dos próprios desenhos. De acordo com May (2019, p. 50),

[...] ao contrário das fotografias, nas quais a luz cénica se torna visível durante a exposição química, toda a imagética [digital] constitui-se como um processo de detecção da energia que é emitida por um ambiente, moldando-a como um conjunto de cargas eléctricas designadas de sinais, que são armazenados, calculados, geridos, e também manipulados de acordo com vários métodos estatísticos.

Pela minha parte, creio que essa ideia pode aplicar-se aos meios e tecnologias digitais em geral. Se a fenomenologia se mostra como a disciplina que lida com as aparências, a minha abordagem aos meios e às tecnologias digitais poderá ser designada como uma antifenomenologia. De facto, acredito que a aparência do digital, especialmente nas suas manifestaçóes enquanto social web, não nos diz muito acerca da sua ontologia, assim como não o faz acerca dos efeitos de subjectivação que sobre nós exerce. A minha ideia sugere que, por detrás de todas as formas de representação online do sujeito, detrás de todas as interacçóes sociais, não se encontra nada mais para além das bases de dados e dos algoritmos. No digital, tal como hoje está delimitado, o que se encontra na sua superfície conta apenas na medida em que pode ser subsumido a sinais, quantificaçóes e classificações.

Penso que existe aqui uma espécie de paradoxo que, noutro texto, designei de "personalização sem personalidade" (ROMELE; RODIGHIERO, 2020). Por um lado, os serviços online são cada vez mais personalizados. Por outro, essa personalização acaba também por eliminar as nossas personalidades. O termo "personalidade" é aqui compreendido à luz de Simondon. O filósofo francês distingue entre individuação, individualização e personalidade. Individuação e individualização são duas formas de diferenciação que são levadas a cabo pelos seres, para se distinguirem do seu meio-ambiente. A 
primeira diz respeito a todos os seres, enquanto a segunda concerne somente aos seres humanos. A personalidade é aquilo que dá a cada individualização uma coerência específica, um estilo, uma orientação. O big data e os algoritmos desmembram as personalidades em tendências, gostos etc. e reagrupam-nos em aglomerados. Os meios e tecnologias digitais são indiferentes às nossas acçôes, ou contam apenas na medida em que podem ser utilizadas para prever acçóes futuras, assim como aquelas de pessoas que, por alguma razão, podem ser consideradas semelhantes a nós.

Tudo isso começou numa data muito específica, 13 de abril de 2007, quando a Google adquiriu a DoubleClick, uma empresa de publicidade direccionada, por 3,1 bilióes de dólares. A partir desse momento, os dados transformaram-se em negócio, na principal comodidade do capital digital, tendo assim também começado aquilo que Cheney-Lippold (2017) designou de "Guerra dos Dados" (Data Wars).

As classificações digitais são, certamente, mais complexas e meticulosas do que as classificaçôes bourdieusianas das classes sociais. Cheney-Lippold alude oportunamente a "identidades interseccionais" e a uma "perspectiva protocategorial”. Contudo, acredito que essa versão mais suave de organizar as coisas e as pessoas não deve ser confundida como uma maior liberdade na expressão do sujeito. Em primeiro lugar, porque maximiza a indiferença mediante a forma como os indivíduos se responsabilizam por si mesmos. Em segundo lugar, porque se torna muito mais adaptativa, com o decorrer do tempo. A sua principal consequência mostra-se com a submissão dos indivíduos aos seus comportamentos presentes mais previsíveis.

De entre os vários exemplos que tenho em mente, considere-se o Tinder. Até muito recentemente, o Rating Elo desempenhou um papel importante nesta app de encontros. No mundo do xadrez, o termo é utilizado para avaliar os jogadores de acordo com o seu nível de competências. Um sistema de avaliação, designado de "pontuação de Elo", por internos da empresa, analisava os utilizadores do Tinder, de modo facilitar correspondências mais adequadas entre os utilizadores, com uma pontuação de desejabilidade similar. Tal como caracterizado no habitus social de Bourdieu, o habitus digital do Tinder faz com que o utilizador deseje apenas o que (ou, neste caso, quem), de acordo com o seu estatuto, poderá ter acesso. De facto, o Tinder não apresenta os mesmos perfis, pela mesma ordem, às pessoas que se encontram na mesma área geográfica no mesmo momento. Os utilizadores são distribuídos de acordo com categorias e níveis, baseando-se no número de pessoas que "deslizaram para a direita" em 
perfis desejáveis. Este não é, contudo, o único parâmetro: os utilizadores são, por exemplo, categorizados em um nível fotográfico e provavelmente também com base na educação e na informação que é voluntariamente fornecida no perfil, com base nos conteúdos das mensagens trocadas, entre outros. ${ }^{8}$

\section{Conclusāo}

Há três tipos possíveis de resposta que podem ser dadas ao problema da nossa habituação online. Em vez de desenvolver o modo como se opóem, proponho-me aqui articulá-las. A primeira consiste em dizer que tal tipo de habituação não constitui um problema. Os seres humanos criam constantemente hábitos, na sua interacção com as várias instâncias sociais e culturais onde se inserem, e os meios e tecnologias digitais são apenas extensóes desses hábitos sociais e culturais, embora criados por outras vias. Poder-se-á mesmo dizer que os meios e tecnologias digitais são, nesse sentido, terapêuticos. Os seres humanos iludiram-se com eles a pensar que são "autênticos", "atenciosos", "criativos" e até "responsivos". Contudo, quando um algoritmo consegue criar arte que é apreciada (e vendida) no mundo da arte, quando um outro se revela capaz de prever o sucesso de um jovem artista, não estaremos antes a descobrir que somos criaturas de hábitos, mesmo nas nossas mais originais formas de expressão?

Proponho que se compreenda esta primeira resposta à luz da suposição ricoeuriana, segundo a qual explicar mais significa compreender melhor. Por outras palavras, defendo que, de facto, os meios e tecnologias digitais fornecem, hoje, não só uma melhor oportunidade de compreender os nossos hábitos e determinaçóes, mas também, e por consequência, a criação de uma separação mais precisa entre a mesmidade e a ipseidade ou, na terminologia hermenêutica, entre interpretaçôes neutras e interpretaçóes vivas.

O segundo tipo de resposta consiste em levar a cabo uma série de acçóes individuais ou comunitárias, desvios ou tácticas. Refiro-me aqui a práticas como a abstinência digital, hacking, entre outras. Tenho também em mente a possibilidade de um incremento da literatura em ética das virtudes da tecnologia (VALLOR, 2016). Antes do fenómeno da aceleração tecnológica

8 Um outro exemplo muito interessante (e também muito eficaz) é o do algoritmo do Spotify. Curiosamente, o Spotify lançou recentemente uma taste breakers playlist, cujo propósito consiste em criar um "alargamento dos horizontes" do seu utilizador. Poder-se-á afirmar que essa playlist representa já por si uma tentativa de domesticar até aquilo que é inesperado. 
— e, com toda a certeza, poder-se-á dizer que os meios e as tecnologias digitais se encontram no seu núcleo —-, Rosa referiu-se à questão da "ressonância". Se a alienação é a impossibilidade de criar uma relação com os outros, a ressonância é o seu oposto, nomeadamente o cultivo da reciprocidade e da mútua transformação que se dá entre um sujeito e o seu mundo (LIJSTER; CELIKATES; ROSA, 2019). Poderemos nós habituar-nos a um uso ressonante dos meios e tecnologias digitais?

$\mathrm{Na}$ minha opinião, a limitação desse segundo tipo de crítica manifestase no risco de criação de um elitismo. Não é por acaso que é nos segmentos mais cultos da população que o desdém pela alta tecnologia se apresenta com mais veemência. Na introdução inglesa de A Dominação Masculina, de 1998, Bourdieu (1998, p. viii, grifos meus) fala de uma “[...] mobilização estritamente politica, que iria abrir para as mulheres a possibilidade de uma acção colectiva de resistência orientada para um conjunto de reformas legais e políticas." Tal mobilização, indica logo a seguir (1998, p. vii):

[c]ontrasta tanto com a resignação que é encorajada por todas as visôes essencialistas (biológicas ou psicanalíticas) da diferença entre os sexos como com uma resistência que se vê reduzida a actos individuais ou aos intermináveis "acontecimentos" discursivos que são recomendados por algumas teóricas do feminismo - estas heróicas rupturas na rotina diária, tais como as "performances paródicas" recomendadas por Judith Butler, esperam, provavelmente, demasiado dos resultados escassos e incertos que obtêm.

Em vez de opor, tal como Bourdieu o fez, as críticas individuais às colectivas, proponho aqui a sua articulação a partir da definição ricoeuriana da ética como uma "vida boa, com e para os outros, dentro das minhas próprias instituiçôes.” Na minha interpretação, o cultivo de uma ética das virtudes da tecnologia não pode ser constituída como um fim em si mesma. Cada acção virtuosa deverá, por assim dizer, aspirar a tornar-se uma acção exemplar para os outros. E cada acção exemplar deverá aspirar a ser vista e apropriada pelas instituiçóes públicas.

No contexto da Teoria Crítica, o termo "instituição" encontra-se, muitas vezes, de mão dada com os termos "ideologia", "coerção" ou "ilusão". Mas a história mais recente do digital, na Europa, acabou também por se caracterizar pela capacidade e pela vontade de algumas instituiçóes em adoptar iniciativas exemplares. Tenhamos em mente, por exemplo, as iniciativas legais 
levadas a cabo por Costeja Gonzáles e Max Schrems, os quais trouxeram até nós a Regra do Direito ao Esquecimento, do mesmo modo que a declaração pelo Tribunal de Justiça da União Europeia pela invalidação da Estrutura Safe Harbor. Estou ciente de que a ideia de instituiçóes justas, tanto no contexto digital como na sua perspectiva geral, merece uma discussão mais aprofundada. Aqui, a título de conclusão, limito-me a dizer que o objectivo de um tal tipo de justiça consiste numa melhoria das condiçóes de possibilidade legais, sociais e tecnológicas, para a prática de um ethos de distanciamento dos nossos habitus digitais.

ROMELE, A. Digital hermeneutics as hermeneutics of the self. Trans/form/ação, Marília, v. 44, p. $185-206,2021$. Dossier Tecnica.

\begin{abstract}
In this article, the author deals with the status of the self and personal identity in the digital milieu. In the first section, he presents his general approach to digital media and technologies, which he has called "digital hermeneutics." He distinguishes between three perspectives in digital hermeneutics, namely the deconstructive, epistemological, and ontological approaches. In the second part, he focuses on digital hermeneutics as hermeneutics of the self. He compares Paul Ricoeur's narrative identity to Pierre Bourdieu's habitus. His first thesis is that the habitus can be seen as a concept of subjectivation that neglects an important part of the subject. Narrative identity offers, in this sense, a remedy to such negligence. His second thesis is that today's digital media and technologies are closer to the Bourdieusian habitus than to the Ricoeurian narrative identity. In other words, digital machines and technologies are "habitus machines" both in their structure and in their effects.
\end{abstract}

Keywords: Digital Hermeneutics. Self. Emagination. Habitus. Narrative Identity.

\title{
REFERÊNCIAS
}

BACHIMONT, B. Le sens de la technique. Paris: Les Belles Lettres, 2011.

BARTHÉLÉMY, A. Herméneutiques croisées: Conversation imaginaire entre Ricœur et Foucault. Etudes Ricœuriennes/Ricoeur Studies, v. 1, n. 1, p. 55-67, 2010.

BOLTANSKI, L. et al. L'effet Ricœur dans les sciences humaines. Esprit., p. 40-64, mar./ abr. 2006. Disponível em: https://esprit.presse.fr/article/boltanski-luc-et-dosse-francoiset-pharo-patrick-et-quere-louis-et-thevenot-laurent-et-michael-foessel-et-francois-hartog/ l-effet-ricoeur-dans-les-sciences-humaines-table-ronde-13278. Acesso em: 9 set. 2020.

BOURDIEU, P. Outline of a Theory of Practice. Cambridge: Cambridge University Press, 1977. 
BOURDIEU, P. L'illusion biographique. Actes de la recherche en sciences sociales, v. 62, n. 63, p. 69-72, 1986.

BOURDIEU, P. Masculine Domination. Stanford: Stanford University Press, 1998.

CAPURRO, R. Digital Hermeneutics: An Outline. AI \& Society, v. 35, n. 1, p. 35-42, 2010. Disponível em: http://www.capurro.de/ digitalhermeneutics.html. Acesso em: 1 jun. 2020.

CHENEY-LIPPOLD, J. We Are Data. New York: NYU Press, 2017.

CORCUFF, P. Les nouvelles sociologies. Paris: Nathan, 2005.

DE MUL, J. Cyberspace Odyssey: Towards a Virtual Ontology and Anthropology. Newcastle upon Tyne: Cambridge Scholars, 2010.

FLICHYl, P. The Internet Imaginaire. Cambridge, MA: The MIT Press, 2007.

FORNET-BETANCOURT, R. et al. The Ethic of Care for the Self as a Practice of Freedom: an Interview with Michel Foucault on January 20, 1984. Philosophy \& Social Criticism, v. 12, n. 2-3, p. 112-131, 1987.

FRAIBERGER, S. P. et al. Quantifying Reputation and Success in Art. Science, v. 362, n. 6416, p. 825-829, 2018.

GEORGES, F. Representation de soi et identité numérique. Réseaux, v. 2, n. 154, p. 165-193, 2009.

IHDE, D. Technology and the Lifeworld. Bloomington and Indianapolis: Indiana University Press, 1990.

LATOUR, B. We Have Never Been Modern. Harvard: Harvard University Press, 1993.

LEIBOVICI, M. De Ricœur à Foucault: en finir avec l'herméneutique du soi? Tumultes, v. 2, n. 43, p. 107-121, 2014.

LEONELLI, S. Data-Centric Biology. Chicago: The University of Chicago Press, 2016.

LIJSTER, T.; CELIKATES, R.; ROSA, H. Beyond the Echo-chamber: An Interview with Hartmuth Rosa on Resonance and Alienation. Krisis, v. 1, p. 64-78, 2019.

MAY, J. Signal, Image, Architecture. New York: Columbia University Press, 2019.

MICHEL, J. Ricoeur and the Post-structuralists. Lanham: Rowmann \& Littlefield, 2014.

RICOEUR, P. Oneself as Another. Chicago: The University of Chicago Press, 1988.

RICOEUR, P. Time and Narrative 3. Chicago: The University of Chicago Press, 1992.

ROMELE, A. Digital Hermeneutics. New York and London: Routledge, 2019.

ROMELE, A.; RODIGHIERO, D. Digital Habitus; or Personalization without

Personality. Humana.Mente, v. 13, n. 37, p. 98-126, 2020. 
ROMELE, A.; SEVERO, M.; FURIA, P. Digital Hermeneutics: from Interpreting with Machines to Interpretative Machines. AI \& Society, v. 35, p. 73-86, 2020.

TRUC, G. Narrative Identity Against Biographic Illusion: The Shift in Sociology from Ricoeur to Bourdieu. Etudes Ricœuriennes/Ricoeur Studies, v. 2, n. 1, p. 150-167, 2011.

VALLOR, S. Technology and the Virtues. Oxford: Oxford University Press, 2016. 
ROMELE, A. 